Behavior and Social Issues, 24, 39-55 (2015). (C) Camila Muchon de Melo, Marina Souto Lopes Bezerra de

Castro \& Julio C. de Rose. Readers of this article may copy it without the copyright owner's permission, if the author and publisher are acknowledged in the copy and the copy is used for educational, not-for-profit purposes. doi: $10.5210 /$ bsi.v.22i0.4207

\title{
Some Relations Between Culture, Ethics And TECHNOLOGY IN B. F. SKINNER
}

\author{
Camila Muchon de Melo ${ }^{1}$ \\ Universidade Estadual de Londrina, Brazil \\ Marina Souto Lopes Bezerra de Castro and Julio C. de Rose \\ Universidade Federal de São Carlos, Brazil
}

\begin{abstract}
B. F. Skinner was engaged, throughout all his career, in finding ways to make life, culture and the world better through behavior analysis. The tools developed by the science of behavior may be used for technological ends. At the same time, a philosophy-Radical Behaviorism-discusses the theoretical basis for science and its possible relations with technology. Ethics emerges from these relations and Skinner had to face inevitable ethical questions. We will examine some aspects of Skinner's radical behaviorist approach on ethics and the relations established between science, technology, culture and ethics. The technology of teaching, proposed by Skinner in 1968, will be addressed as the best example of a behavioral technology which, as a cultural intervention, based on behavioral science, may contribute to achieve ethical goals: in others words, to build a better life and a better world - according to Skinner's understanding of "better."

KEYWORDS: behavioral technology, culture, ethics, radical behaviorism, technology of teaching
\end{abstract}

Let me ask you a question. I warn you, it will be the most terrifying question of your life. What would you do if you found yourself in possession of an effective science of behavior? Suppose you suddenly found it possible to control the behavior of men as you wished. What would you do? (Skinner, 1948/2005, p. 240)

\footnotetext{
${ }^{1}$ Supported by the São Paulo Research Foundation (FAPESP), through a postdoctoral fellowship to the first author (FAPESP, Grant 2008/56801-3) and a doctoral fellowship to the second author (FAPESP, Grant 2008/57160-1). The third author has a Research Productivity grant from the Brazilian National Research Council (CNPq). The authors are affiliated to Instituto Nacional de Ciência e Tecnologia sobre Comportamento, Cognição e Ensino, which provided support for preparation of the manuscript through Grants from $\mathrm{CNPq}$ (573972/2008-7) and FAPESP (Grant 08/57705-8). We thank Guilherme Bergo Leugi for help in translating the manuscript into English. This manuscript benefited greatly from the valuable observations and suggestions by two anonymous reviewers on an earlier version of this work. Author contact: Camila Muchon de Melo, Departamento de Psicologia Geral e Análise do Comportamento, Universidade Estadual de Londrina. Caixa Postal: 10011, CEP: 86.057-970, Londrina/PR, Brazil. email: camuchon@hotmail.com
} 


\section{MELO, CASTRO, \& DE ROSE}

Skinner was concerned with the application of behavioral science to solve important human problems, such as overpopulation, nuclear war, pollution, equal rights and opportunities for women and more (e.g., Skinner, 1987, 1971/2002, 1948/2005). He maintained that the solution to these problems required the modification of behavior and, therefore, a technology of behavior. How is it possible to make polluters throw their waste in appropriate places, or to make a couple prevent unexpected pregnancy? Other sciences may generate technology to solve problems such as pollution or overpopulation, but applying these technologies is a behavioral issue (Skinner, 1971/2002). ${ }^{2}$ For instance, many people do not use condoms in all sexual relations despite ample knowledge that condoms can prevent sexually transmitted disease and undesired pregnancy. How to make people use condoms exemplifies issues that require a technology of behavior to be solved.

Technology aims at the deliberate production of consequences (Melo, 2008). Thus, behavioral technology can contribute to solve current problems such as birth control, environmental preservation, reduction of malnutrition worldwide, improved sanitation and health, and so on (Skinner, 1987, 1971/2002).

However, the development and proposed application of a technology of behavior, particularly one that may promote cultural planning, has triggered heated opposition and ethical questioning. Deliberate control of human behavior challenges the traditional conceptions of free will and freedom (Skinner, 1971/2002). Moreover, it carries the threat of enslaving the controlees to benefit only the controllers. However, according to ontological and epistemological principles of Radical Behaviorism, behavior is always controlled, deliberately or not. In his utopian novel Walden Two, Skinner presents us with the possibility of building a whole society (albeit small), with its planned culture, by means of a technology of behavior. Skinner claims that such a culture would guarantee survival and happiness for its members (a claim that would probably be endorsed by many behavior analysts and radical behaviorists). Such possibility of total control of human behavior is, nevertheless considered a nightmare by its critics. Skinner himself embodied these criticisms in Castle, a philosopher visiting Walden Two. The epigraph of this manuscript is a question made to Castle by Skinner's alter ego Frazier, who planned and founded Walden Two. Castle answers he would "throw the science of behavior in the ocean." Therefore Frazier inquiries him and the dialogue proceeds (Skinner, 1948/2005):

- And deny men all the help you could otherwise give them? [Frazier]

- And give them the freedom they would otherwise lose forever! [Castle]

- How could you give the freedom? [Frazier]

- By refusing to control them! [Castle]

- But you would only be leaving the control in other hands. [Frazier](p. 240)

Skinner is convinced that behavior analysts have mastered a technology of behavior and not using it would be negligent, because power to do that would be delegated to others (Skinner, 1953/1965). Therefore, the dialogues between Frazier and Castle summarize the debate between

\footnotetext{
${ }^{2}$ See Lehman and Geller (2004) for an interesting analysis of application of a technology of behavior to protect the environment.
} 
advocates of a behavioral technology and its critics, particularly those concerned with political, philosophical, and ethical issues. Skinner later dedicated a whole book to address these issues, his 1971 essay, Beyond Freedom and Dignity ( Skinner, 1971/2002).

These topics are thus inevitable when Skinner advocates cultural planning based on a deterministic science, as can be seen in Walden Two (Skinner, 1948/2005). Cultural interventions based on a technology of behavior require decisions about what is better for the people, for the culture. Can a science tell us the best criteria for these decisions? Furthermore, if it tells us, does it not put itself at risk of losing its scientific status, becoming prescriptive rather than descriptive? How does Radical Behaviorism deal with questions about what is good, what is better for people and their culture? These are questions about values, about what is better and what should be done. Is there a radical behavioristic ethics that could establish values to guide large-scale interventions on human behavior such as the design of a culture? Could such ethics determine objectives for a cultural intervention? And how should a technology of behavior be used to achieve these goals?

In this context, the present article seeks to contribute to a critical philosophical analysis of some relations between culture, ethics, and technology in Skinnerian Radical Behaviorism, in other words, in the philosophy that Skinner advocated for the science of behavior. In order to do this, we will initially discuss what could be construed as the Skinnerian ethics, which comprises both descriptive and prescriptive aspects, the latter ones strongly related to the good of the group. We will briefly discuss some of the contributions and possible inconsistencies of this ethics. We will then deal with educational technology as an example of behavioral technology committed to Skinner's prescriptive ethics. Although other examples could be found in behavioral technology, we choose to focus on educational technology because survival of the culture seems to require an educational technology that teaches individuals to think, solve problems, be creative, and free themselves from certain kinds of environmental control.

\section{Ethical Issues in Skinner's Radical Behaviorism}

Ethics is a multifaceted and controversial field. According to Proudfoot and Lacey (2010), its subject matter is, for teleologists, the good (or what is considered good, the goods, the values), and, for deontologists, the duty (or duties). Ethical questions are generally divided into two groups, usually contrasted as: ethics/morals, or metaethics/ethics, or philosophical ethics/normative ethics, or metaethics/normative ethics. According to Proudfoot and Lacey, this is a distinction between talking about ethics and talking ethically, between views of ethics and views in ethics.

Thus, ethics may be approached as a field of investigation, called metaethics, which involves predominantly descriptive propositions. Parallel to metaethics, there is another meaning for ethics: prescriptive ethics, which is normative, at times known as morals, involving predominantly imperative propositions. On the basis of these definitions, metaethics may be understood as the study of morals.

We can say that Skinner's ethics presents itself in these two senses. However, whereas his metaethics is explicit, ${ }^{3}$ the moral component of his ethics is implicit, not recognized as such by himself, and this introduces a degree of tension in his texts.

\footnotetext{
${ }^{3}$ It is explicit in the sense of being clear. However, Skinner never used the term metaethics.
} 
MELO, CASTRO, \& DE ROSE

\section{A Science of Values and Moral Behavior - a Metaethics}

Skinner (1953/1965, 1971/2002) considered that moral or ethical behavior ${ }^{4}$ was also included in the object of a science of behavior. This science has among its tasks, therefore, to investigate how behaviors are classified as ethical or not, and how individuals acquire such behaviors. Also in the field of metaethics, Skinner developed an interpretation of the nature of values (goods). They are also legitimate objects of a science of behavior because they control behavior. We may consider, then, that a science of behavior contains a science of values and of moral behavior. ${ }^{5}$

To provide a scientific approach to values, a controversial philosophical issue must be faced: the fact-value distinction. Is there an ontological difference between statements of facts and statements of values? Leigland (2005) argued that Skinner does not recognize an ontological distinction between statements of facts and statements of values.

Skinner's Radical Behaviorism, by sharing features with philosophical pragmatism (see Dewey, 1929; Murphy; 1990; Rorty, 1979), regards values as behavioral phenomena, analyzed, like other behavioral phenomena, as the interaction between organism and environment. In this sense, there is no dichotomy between facts and values. Values belong to the factual world.

Could we, then, refer to a radical behaviorist metaethics as an empirical ethics? We think so. What is a value, what is good or what benefits an individual or a group of individuals, have this status because of phylogenic, ontogenetic, and cultural histories. According to Skinner: "What a given group of people calls good is a fact: it is what members of the group find reinforcing as the result of their genetic endowment and the natural and social contingencies to which they have been exposed" (Skinner, 1971/2002, p. 128, emphasis added). Then, "things are good (positively reinforcing) or bad (negatively reinforcing)" (Skinner, 1971/2002, p. 104) and "good things are positive reinforcers" (Skinner, 1971/2002, p. 103), "what is good for the individual is what promotes his well-being" (Skinner, 1974/1976, p. 226). Skinner draws a parallel to the phylogenic and cultural levels: "What is good for the species is what make for its survival. . . .What is good for a culture is what permits it to solve its problems" (Skinner, 1974/1976, p. 226). In this sense, what has value for a culture is what contributes to its survival.

We can thus identify, in Skinner's metaethics, a classification for the kinds of values. According to Ruiz and Roche (2007):

The items on a list of values can be classified under three headings: personal good, owing to our biological susceptibility and genetic endowment; the good of others, derived from social reinforcement for positive social behavior; and the good of the culture, and the measures the culture uses to induce its members to work for its survival. (p. 3)

Therefore, Skinner distinguishes three kinds of "good." They all refer to consequences, but may be distinguished by who is mostly affected by the consequences. According to Dittrich and Abib (2004), personal goods are

reforçadores positivos em relação ao comportamento da pessoa que os produz. . . . Bens dos outros são aqueles que, ainda que produzidos por certo indivíduo, resultam em

\footnotetext{
${ }^{4}$ We use "moral behavior" and "ethical behavior" as synonyms.

${ }^{5}$ Some critics argue that Skinner failed in producing an adequate explanation of values (Plumb, Stewart, Dahl \& Lundgren, 2009).
} 
reforçamento positivo para o comportamento de outras pessoas que não o próprio indivíduo. . . . Bens das culturas são todas as conseqüências de práticas culturais que contribuem para a sobrevivência da cultura que promove tais práticas. (p. 427)

After this brief explanation of the question of values, we may address moral behavior. People can act under control of personal goods, the good of others and the good of the culture. Each one of these goods may influence individual behavior. Moral behavior may consist of moral actions, those considered socially correct, or of value judgments: "To make a value judgment by calling something good or bad is to classify it in terms of its reinforcing effects" (Skinner, 1971/2002, p. 105). This applies also to value judgments based on feelings:

When we say that a value judgment is a matter not of fact but of how someone feels about a fact, we are simply distinguishing between a thing and its reinforcing effects. Things themselves are studied by physics and biology, usually without reference to their value, but the reinforcing effects of things are the province of behavioral science, which, to the extent that it is concerned with operant reinforcement, is a science of values. (Skinner, 1971/2002, p. 104, emphasis added)

This science seeks to explain why each individual advocates for, claims to possess, or has the behavior governed by certain values. First of all, we inherit from phylogenesis a certain biological structure, which has certain susceptibilities. Humans are susceptible to pleasure and to having their behavior reinforced by some events, such as water, food, sexual contact, warm places, and so on. All these events had survival value for the species, so those organisms most likely to be reinforced by such events have survived and their descendants also have such susceptibilities. We call these events "good". Therefore we say that some values have phylogenic origin.

Throughout ontogeny the "naturally" selfish individual goes through numerous natural and social contingencies, many of them established by the culture. It is possible then that $\mathrm{s} /$ he begins to act, at times, under control of "the good of others" (Skinner, 1971/2002, p. 109). In other words, many contingencies are established to generate behavior under control of what is reinforcing to others. These "others" may vary depending on the context and, therefore, good and bad behavior may be labeled differently in different contexts. Thus, in a religious context, "good" and "bad" become "pious" and "sinful"; at school, "right" and "wrong" (e.g., Skinner, 1953/1965, 1971/2002).

Skinner points out that feelings associated with ethical behavior do not cause the behavior. "Stimuli are reinforcing and produce conditions which are felt as good for a single reason, to be found in an evolutionary history. Even as a clue, the important thing is not the feeling, but the thing felt" (Skinner, 1971/2002, p. 107). As an example: an individual supports the government due to the contingencies established by the government, a controlling agency, and not because $\mathrm{s} / \mathrm{he}$ is a loyal citizen, or has loyalty. We say that $\mathrm{s} / \mathrm{he}$ is loyal and teach him or her to call

\footnotetext{
6 "positive reinforcement on the behavior of the person who produces it. . . Goods of others are those which, although produced by a certain individual, result in positive reinforcement for the behavior of people other than the individual. . . Goods of the culture are all the consequences of cultural practices that contribute for the survival of the culture which promote such practices." (Dittrich \& Abib, p. 427, our translation)
} 


\section{MELO, CASTRO, \& DE ROSE}

himself or herself loyal and report any special conditions which feel like loyalty (Skinner, 1971/2002).

Therefore, we often deal with the "other" as an organized group, as the controlling agencies, which were described by Skinner (1953/1965). In this case, the intentional control for the good of others becomes more powerful when it is exerted by religious, governmental, economic and educational organizations. According to Skinner (1987, p. 7): "Governments, religions, and capitalistic systems, whether public or private, control most of reinforcers of daily life, they must use them, as they have always done, for their own aggrandizement, and they have nothing to gain by relinquishing power." Other social contingencies may lead us to act for the good of the culture as a whole and not just for the good of an "other," or an "other" organized as a controlling agency (Skinner, 1971/2002).

An important feature of Skinner's metaethics is moral relativism. There is no absolute good or evil. Events acquire functions and classifications for an individual as a result of her/his phylogenic repertoire and of contingencies to which s/he is submitted along ontogenesis, particularly social contingencies. The same moral relativism is valid for cultures: since each group of people has its own genetic, natural and social contingencies, what is good or of value for one group may not be so for another (Skinner, 1971/2002).

\section{Ethics of Behavioral Technology-A Prescriptive Ethics: Morals}

In spite of the moral relativism of his metaethics, Skinner, as we have seen since Walden Two, was concerned about solving human problems with the help of behavior analysis. Skinner (1971/2002, p. 150) states that behavioral technology is ethically neutral, because nothing in a methodology determines the values that govern its use. Nevertheless, he claims: "We are concerned here, however, not merely with practices, but with the design of the whole culture, and the survival of a culture then emerges as a special kind of value" (Skinner, 1971/2002, p. 150, our emphasis).

We understand from statements such as this that Skinner argues that moral neutrality cannot, or should not, exist in the sphere of cultural planning. It does not make sense to intervene without an objective, without an idea of what is best to be done. The behavior of whoever intervenes is guided by a prediction of the intervention's consequence. And whenever we determine what is best to be done, what ought to be done, we move to the domain of imperative ethics, which is prescriptive, not relativistic. The moral relativism of a science of values is no longer in place. ${ }^{7}$

Therefore, in the sphere of social intervention, there should be a special value that governs the use of technology, helping to define what is good and what is bad. For Skinner, this value is the good of culture, the survival of the culture (that would be ultimately defined by survival of humanity, because Skinner does not prescribe any type of competition between cultures), that should be above other values. According to Ruiz and Roche (2007), "in Skinner's naturalistic ethics, survival emerges as the ultimate value and criterion by which to assess the worth of

\footnotetext{
${ }^{7}$ With moral relativism only, we would not have reasons to be against, for instance, dictatorships or tyrannical governments. Evidently, Skinner is against such governments, but from a purely scientific or metaethical standpoint, there would be nothing against such government systems. As Skinner points out, nothing in a methodology determines the values that govern its use.
} 
cultures and individual cultural practices" (p. 1-2). Skinner (1971/2002) argues that this good should govern the behavior of those who are in a position to design cultural practices.

As Frazier in Walden Two, we can produce cultural "mutations" with new cultural practices, and we can modify the conditions under which they are selected by modifying the environment in which humans live. Skinner (1969b) defends that this should be made deliberately and that we should not expect cultural evolution to occur "naturally" through "happy accidents." Thus, Skinner advocates for cultural planning and states that a well-designed culture is "a set of contingencies of reinforcement under which members behave in ways which maintain the culture, enable it to meet emergencies, and change it in such a way that it will do these things even more effectively in the future" (Skinner, 1969b, p. 41).

The prescription of the good of culture as a supreme value in Skinnerian writings raises, however, some problems. If, on the one hand, the election of good of the culture seems tautological (after all, what would be at stake in cultural designing if not the survival of the culture itself?), on the other hand, upon further analysis, we could find other kinds of goods to guide cultural planning. Radical Behaviorism as a philosophy of the science of behavior states necessary but not sufficient assumptions for the election of the good of culture. Thus, despite the efforts of Skinner to convince us otherwise, it is possible to use the theoretical and technological framework of the science of human behavior for purposes other than the good of the culture. No other values are being defended here, yet we argue that the prescriptive aspect of Skinner's theory does not necessarily stem from the descriptive aspect. As Chiesa points out, survival may be an important value for Skinner, whose humanistic tendencies are well known. However, "la filosofía y la práctica científica del conductismo no conduce inevitablemente a promocionar la supervivencia como un valor. (...) Sin embargo los valores no emergen de la meta-ética" (Chiesa, 2003, p. 296). ${ }^{8}$

In this sense, electing the good of the culture does not necessarily stem from the assumptions of Radical Behaviorism. One could argue consistently-without contradicting theoretical assumptions - for cultural planning based on individual goods, where, for example, members of the culture would exploit all natural resources, have unsafe sex and no concern about the future of humanity.

Besides, if we consider the possibility of goods other than survival, we may also question whether a culture that survives is necessarily good. If the Third Reich had survived and thrived, it might have produced individuals that would feel happy under that culture. For those individuals, survival of such a culture would seem a value worth pursuing, and would not be incompatible with other values such as happiness, progress, health, racial purity (certainly a value for individuals of such a culture). However, most people in our present culture, including radical behaviorists, would consider the culture engendered by the Third Reich as evil, and not because it did not survive. Had it survived, we would probably consider it even more evil. Skinnerian emphasis on survival sounds very appropriate for our time, in which human behavior is threatening the survival of the species and the planet. We may even accept that survival is the only value according to which a culture will eventually be judged. However, since we are not inclined to accept any culture that survives, it is questionable whether survival should be the main value to guide cultural planning.

\footnotetext{
8 "the philosophy and scientific practice of behaviorism do not inevitably lead to the promotion of survival as a value (...) Surely the values do not emerge from the metaethics" (Chiesa, 2003, p. 296, our translation).
} 


\section{MELO, CASTRO, \& DE ROSE}

Skinner seems to be aware of this problem, and cautions that survival should not be promoted at any cost. Happiness or well-being of individuals that make up the culture should be assured. Good cultural planning, therefore, would not demand personal sacrifice.

Personal sacrifice may be a dramatic example of the conflict of interests between the group and its members, but it is the product of a bad design. Under better contingencies behavior which strengthens the culture may be highly reinforcing. (Skinner, 1969b, p. 41)

Thus, in Skinner's prescriptive ethics, ${ }^{9}$ we would have a well-planned culture, by means of a technology of behavior. Such a culture is able to solve the problems which it faces and, at the same time, does not require personal sacrifice from its members, thus guaranteeing survival and happiness (e.g., Skinner, 1948/2005).

\section{An Ethical Technology}

Based on what was discussed in the previous section, we may consider that a behavioral ethical technology is one whose goals ultimately seek the survival of humanity, in balance with the welfare of individuals. The absence of this balance would be, according to Skinner (1953/1965), an example of bad design. Skinner (1971/2002) does not advocate survival of cultures at the expense of tyrannical, coercive, or exploitative practices. The science of behavior, in this sense, has a role in predicting which cultural practices will have the higher chance of being effective according to the goals.

Skinner indicated how a technology of behavior could be useful for this endeavor. Such technology should be prepared to intervene (a) on problems arising from human susceptibilities that have been phylogenically inherited, (b) in the gaps between immediate and delayed contingencies, and (c) in the production of flexible cultural practices (that may be stable and, at the same time, amenable to innovation depending on the contingencies). Education would be extremely important to achieve these objectives. Creative behavior, problem solving, and freedom from certain kinds of control that compete with adequate environmental control, may be produced by a technology of teaching.

Since Skinner considers behavior to be determined by histories of variation and selection at three levels, he attributes many current behavioral problems to characteristics of the processes of variation and selection (Skinner, 1966/1969a, 1975/1978, 1981, 1990). Some susceptibilities were important when people lived in environments where there were food shortages, populations were extinguished by hunger and pestilence, and individuals struggled to protect themselves from attacks by other individuals and groups. However, those inherited susceptibilities, when interacting with the environmental contingencies in which we live today, resulted in serious problems. Examples of these are: obesity, overpopulation and the invention of weapons that can

\footnotetext{
9 The ethics of behavioral technology has other important aspects. It may be classified as experimental, according to the arguments to be addressed in subsequent sections. Again an example, albeit fictional, is the cultural design described in Walden Two (Skinner, 1948/2005), where there are no right or wrong practices $a$ priori, but a constant testing of new practices developed by some planners, who have their planning behavior controlled by the core value: the good of the culture. The ethical technology should try to predict the survival value of cultural practices, in other words, the chances of any given practice to strengthen the culture, to contribute to its survival.
} 
damage large numbers of persons. Nevertheless, Skinner (1987) argued that behavioral technology could intervene on the processes of variation and selection by introducing new variations or changing selective contingencies.

Another phylogenic characteristic that must be addressed by a behavioral technology is the reduced reinforcing value of delayed consequences relative to immediate ones. Many of our current global problems are due to behaviors that are strengthened by immediate consequences despite harmful long-term consequences. An example is global warming. Driving my own car to go to work results in a shorter ride and I also avoid wasting time waiting for buses or arranging a car pool. The same reinforcing effects affecting the behavior of millions of people, however, result in pollution and gases that produce the greenhouse effect. ${ }^{10}$ These harmful consequences, however, are much delayed and not clearly connected to the behaviors that produce them. One of the functions of cultures is probably to supplement or counteract control by immediate consequences in order to avoid harmful long-term consequences. Harris (1974) provided several examples of such cultural prescriptions. For instance, control by immediate consequences would lead people in India to eat beef, with disastrous long-term consequences due to energetic, ecological, and demographic constraints of the Indian environment. It is not clear how the religious/cultural prohibition to eat beef arose, but this cultural practice contributed to avoiding environmental collapse and, therefore, made a strong contribution to the survival of the culture. Diamond (2005) has described such a collapse for a culture that exploited resources beyond the environmental "carrying capacity" (to use Harris' term). As Harris pointed out, the Indian cultural practice increases efficiency in the use of energetic resources in that context. By contrast, the overuse of cars in the Western culture results in a non-efficient use of energy, together with depletion of irreplaceable oil reserves. Our culture probably will not have enough time to wait for the accidental emergence, by variation and selection, of effective cultural prescriptions on the use of private cars.

Skinner $(1953 / 1965,1987)$ also noted that many contingencies are planned for cultures to produce and maintain cultural practices that are in the group's interest. Therefore, controlling agencies - such as religion, government and economic systems-plan positive and negative reinforcements for behavior they consider of interest. The contingencies generated by these agencies overcome control by immediate consequences. As an example, the religious prohibition to eat beef effectively suppresses a behavior that would have powerful immediate reinforcers. The contingencies established by controlling agencies also provide short-term consequences which may effectively bridge the gap between behavior and long-term consequences. The Indian peasant does not refuse to eat beef because of sensitiveness to long-term energetic problems, but because of short-term cultural contingencies. Skinner points out, however, that controlling agencies are often concerned with the survival of the agency, and contingencies that promote survival of the agency are not necessarily consistent with the survival of humanity.

\footnotetext{
${ }^{10}$ It has been argued that the concept of metacontingency is useful to understand how cultural practices are maintained and structures (e.g., Glenn, 1986, 1991, Glenn \& Malott, 2004; Malott \& Glenn, 2006, but see Mattaini, 2006, for a less optimistic view). Empirical and theoretical studies (e.g., Tourinho \& Vichi, 2012; Vichi, Andery \& Glenn, 2009) have suggested interlocking behavioral contingencies produce not only individual consequences, but also aggregate products and cultural consequences, that may generate cultural practices and also cultural problems. However promising the concept may be, this theoretical framework is not within the scope of the present work, and would demand another essay.
} 


\section{MELO, CASTRO, \& DE ROSE}

If the futures of governments, religions, and capitalistic systems were congruent with the future of the species, our problem would be solved. . . . Unfortunately, the futures are different. Nuclear weapons are made to guarantee the survival of governments and religions, not the species. (Skinner, 1987, p. 7)

In this context, Skinner proposes that there are groups not committed to these agencies that would be able to take action to save the world (Skinner, 1987). Often these groups are made up of scholars, scientists, teachers and media writers. Science, for example, would have an important role envisioning a future that does not resemble the past. In addition, Skinner (1987) has argued that we possess a science to design a world that fixes the faults produced by evolution. $^{11}$

Skinner (1953/1965) argued that science can accelerate the "practice of changing the practices." Science can render remote behavioral consequences effective, when it leads us to recognize which practices are most likely to strengthen a culture, especially when faced with adventitious contingencies. Science inspires the "choice" of the good of culture as a value at the expense of traditional values such as the freedom to use cars or the happiness resulting from the possession and use of an expensive and energy-consuming car. Science can explain why we should behave in favor of culture. Thus, science can accelerate planning practices with positive survival value. It is at this point that a technology of behavior would present a significant contribution: it can provide the means to achieve the goals of a cultural design that aims at humanity's survival and at the welfare of individuals, as prescribed by Skinnerian ethics.

Thus, Skinner, as well as many radical behaviorists, claims that behavioral technology can and must serve the strengthening of cultures, which ultimately should promote the survival of mankind (but see Castro, 2013, for possible dangers of the technocratic biases implicit in such a view). Furthermore, Skinner suggests the planning of contingencies that achieve a certain kind of balance between the good of individuals and the strengthening of the culture (Melo, 2008; Melo $\&$ de Rose, 2012).

This technological concern throughout Skinner's work is specially focused in three areas: psychotherapy, education and cultural design, as described in Walden Two (e.g., Skinner, 1953/1965, 1968, 1948/2005). One example, to which we turn now, is educational technology or, in Skinnerian terms, the technology of teaching (Skinner, 1968), perhaps the most promising for an ethical technology.

\section{Technology of Teaching and its Ethical Role}

Skinner's book The Technology of Teaching, even though published more than 40 years ago, in 1968, is not yet outdated in its analysis of problems of the educational system. Moreover, its basic assumptions are yet to be rediscovered in the implementation of effective teaching. This is particularly important at the present time, when computer technology would allow programming of contingencies far more effective than those that were possible in the early days of teaching machines and programmed textbooks.

\footnotetext{
${ }^{11}$ We may question, however, to what extent these groups would, nowadays, be indeed not committed to agencies that hold power and are not concerned with the future of humanity. Although science and technology are needed to solve global problems, we cannot lose sight of the fact that scientific research is increasingly dependent on governmental and corporate funding, the press is also subject to restrictions by governments and corporations, and political factors usually influence what is taught in schools.
} 
Skinner (1968) argued that an appropriate use of educational technology may maximize the potential of learners, in order to make them more skillful, foster creative behaviors and a wide diversity of interests about the world that surrounds them; and finally it may contribute to the development and strengthening of a culture that uses this technology in the design of cultural practices respecting the education of its members.

Thus, it can be argued that the technology of teaching advocated by Skinner (1968), and his emphasis on "teaching students to think", promoting originality and freedom, could be a tool for strengthening the culture. In Skinner's words: "Survival is a difficult value. Ideally a system of education should maximize the chances that the culture will not only cope with its problems but steadily increase its capacity to do so" (Skinner, 1968, p. 232).

Thus, educational technology may work in favor of a better life and a better world. It could not only assure the transmission of the knowledge and wisdom of the culture (i.e., behaviors, verbal of otherwise, that helped the culture to deal effectively with its environment) but also promote creative behavior, problem solving, self-control and self-regulation. Therefore, the technology of teaching is an ethical technology. Rather than being ethically neutral, it would be, as envisioned by Skinner, guided by the goals of producing students that are creative, able to think, original, and free. Being more skillful at solving problems, this student will not only achieve a better life but would contribute to build a better world, participating in the design of better cultural practices.

\section{Teaching Thinking}

One of the major tasks of a culture is the transmission of acquired knowledge and behaviors. It is the transmission of accumulated knowledge that makes a culture possible. Skinner (1968) notes, however, that when a teacher is successful in conveying knowledge and, moreover, transmits conclusions and decisions about issues that could be solved by the students, this teacher produces a "well taught" student - but who had few opportunities to learn how to learn. According to Skinner, knowledge acquired during the history of a culture must be transmitted; however, the student must also learn how to think. This means learning, without being taught, in other words, learning how to learn, to solve problems, exploring the unknown and behaving in an original way.

For Skinner (1968), teaching to think requires the addressing of thinking as a behavior rather than as a mental activity. What we found in traditional education is that the sequence of behaviors that we call thinking is reinforced by consequences contingent solely on its final and overt response, the solution. This method selects only the "successful" student's behavior of reaching a problem's solution, but what about the student who is unsuccessful? It would be necessary to analyze and shape the whole behavioral chain that leads to a solution. According to Skinner (1968) this implies analyzing precurrent behavior: the preliminary responses which modify the environment or the individual himself and which may favor the emergence of the solution. This is easier to do in algorithmic problem solving, but what about heuristic problem solving, in which the solution is still unknown to the community?

To address heuristic problem solving it is necessary to solve the problem of problem solving. According to Skinner (1968), a heuristic technique consists in identifying the part that is really unknown in the problem at hand. This technique can transform a problem into another one, which is most likely to be solved. In heuristic problem solving, problem-solving behavior creates conditions that tend to increase the likelihood of a solution; however, one cannot predict exactly 


\section{MELO, CASTRO, \& DE ROSE}

when such a solution will occur. That does not mean that there are not variables determining the solution. Nor does it mean that the solution is the result of underlying cognitive processes that cannot be taught in order to make students learn to think. In this sense, thinking is also interpreted as heuristic problem-solving. The central question when dealing with thinking as behavior is that thinking, like any other behavior, is a product of genetic and environmental variables and, therefore, can be learned like any other behavior. Skinner (1968), therefore, claims that it is possible to teach students how to think. Moreover, thinking, as solving heuristic problems, opens up a field for discussing the teaching of original behavior.

\section{Technology of Teaching in Promoting Originality}

One of Skinner's concerns regarding the use of an educational technology is the production of creativity, which is directly related to heuristic problem-solving. Creative behavior can strengthen a culture because it produces variations necessary to cultural development. New practices that contribute to solve the problems of a group can be promoted in the formal education of members of the culture. A radical behaviorist approach states that creativity can be produced and, therefore, teaching must generate creative behaviors. Creativity can be found not only in selection but in variation as well (Skinner, 1968). Importantly, here we can also identify the values favored by Skinner: it is important to teach existing knowledge and also to teach students to think, and to produce creative behaviors.

Originality concerns the emission of new behavior. The behavior may be new for the individual, for the whole culture, or for humanity as a whole. It is not the original behavior itself that is taught, since a behavior that is taught is not original, by definition. Nevertheless, we can teach students to arrange environmental contingencies that maximize the likelihood of new and creative responses. Cultures can promote original behavior by selecting original practices at the expense of traditional practices. An example can be found in art and music: "When familiar forms of art and music lose their power to reinforce, new forms are acclaimed just because they are new" (Skinner, 1968, p. 18, emphasis added).

A very accurate transmission of knowledge can reduce the variability of behavior and decrease the likelihood of original responses. The question is not "to transmit or not to transmit", but what methodology will a teacher use for this enterprise. According to Skinner (1968), to promote originality, an educational technology should also enable the student to explore new environments and solve new problems. Quantity of behavior is also relevant, though not sufficient.

Thus, we understand that, in proposing a technology of teaching, Skinner (1968) argues that this technology should have, among its objectives, teaching students how to think and, in this sense, teaching them to solve heuristic problems. In addition, a technology of teaching should teach the student how to produce environments that enable the emergence of creative behavior in their own repertoire. Ultimately, education for creativity can strengthen a culture by producing new cultural practices that solve the problems it has found or is going to find. 


\section{Technology of Teaching in Promoting Freedom}

For Skinner (1968), education is also an important promoter of freedom. ${ }^{12}$ Skinner, of course, does not conceive freedom as free will, an absence of determination. Behavior is always controlled. However, Skinner is interested in the variables that control the use ${ }^{13}$ of the word freedom. The word freedom often refers to getting rid of aversive control (Skinner, 1971/2002). In this case, Skinner $(1953 / 1965,1968,1971 / 2002)$ points out that there are two main kinds of aversive control: one related to the "physical" environment and another to the "social" environment. Therefore, one of the senses of freedom is that of "being free" from aversive control. In this context, education can work for the development of self-control, facilitating the adaptation of individuals as they come into contact with aversive aspects that were not eliminated from the environment.

Skinner points out that positive control may generate delayed aversive control (Skinner, 1971/2002). In this case, people often feel "free"; however they do not identify the aversive conditions that can be later generated. By producing precurrent behaviors that allow selfgovernment, the technology of teaching could enable individuals to escape from positive contingencies whose long-term consequences are aversive; the technology can, thus, produce freedom (Skinner, 1968, 1971/2002).

Skinner (1968/2003, p. 84-85) also deals with freedom in the sense of being free from the control exerted by people. This refers to behaviors that are under the control of the non-social environment, rather than the social one. When education promotes a vast and efficient repertoire, when it teaches students to do tasks without constant teacher assistance, it produces behavior that is "free" from people. When student's behavior is shaped and maintained by the natural consequences of behavior rather than by approval, admiration or attention, we then have an education for freedom.

Therefore, freedom, in a radical behavioristic view, could be understood as the existence of a repertoire that, over the long term, maximally avoids aversive or punishing stimuli and gains some kinds of positive consequences. The technology of teaching has a fundamental role in building behavioral repertoires that produce freedom. In other words, we are free in this sense if we visit a library and know how to read, if we buy a musical instrument and know how to play it, and so on. We are free to have a future if we have a repertoire that allows us to examine our current cultural practices and so, identify practices that potentially cause problems. It is at this point that an ethical behavioral technology is classified as experimental. ${ }^{14}$ As Skinner (1974/1984) pointed out:

\footnotetext{
${ }^{12}$ It is important to underline that Skinner is a critic of the traditional concept of freedom as the absence of any such determination. People can, nevertheless, be free from certain kinds of control, although no one can be free from environment. "Freedom is a matter of contingencies of reinforcement" (Skinner, 1971/2002, p. 37).

${ }^{13}$ Skinner, as well as any behavior analyst, does not conceive of words as something that can be used. However, he observes it would be very cumbersome to write without such expressions.

14 The ethics of behavioral technology may also be classified as experimental. An example, albeit fictional, is again the cultural design described in Walden Two (Skinner, 1948/2005), where there are no right or wrong practices a priori, but a constant testing of new practices developed by planners.
} 


\section{MELO, CASTRO, \& DE ROSE}

The problems of society called for something more, and that was where a behavioral technology could make its contribution. Five other principles were needed:. . . Transmit the culture effectively to new members through expert child care and a powerful education technology.... Regard no practice as immutable. Change and be ready to change again. Accept no eternal verity. Experiment. (p. 346)

\section{Technology of Teaching in Strengthening Culture}

Skinner (1968) emphasizes that education has an important role in ensuring that the student will emit socially acceptable behaviors. Education shares responsibility with ethical, religious and governmental institutions to make the student's ethical behavior appropriate to his or her culture. Many aversive practices were and still are used for those purposes, however. An educational technology based on behavior analysis aims to minimize - if not to eliminateaversive educational contingencies.

Education can facilitate the solution of ethical problems that individuals may encounter in non-educational environments. When a culture needs to teach the resolution of ethical problems so that individuals can create their own rules according to each context, educational systems can facilitate the solution of moral problems that students will face outside school. They can do this by teaching self-control and self-government techniques - that is, teaching students how their behavior works. For Skinner (1968, p. 200): "An educated man is perhaps better able to adapt himself to his environment or adjust to the social life of his group, and a culture which emphasizes education is probably more likely to survive. ..".

But not only is the student's behavior at stake if we want to implement an education that strengthens a culture. According to Skinner (1968), the "behavior of the entire system" influences educational policy. The behavior of those who teach, of researchers and administrators, of those who set of educational policies and who maintain education, in other words, the whole system determines who will be taught, for how long, what content is taught, educational quality, and so on. Behavior analysis should contribute to the educational system so that this system works towards strengthening its culture. In order to design a culture that promotes its own survival we need to identify (a) what problems the culture will have to face (science, in general, has a role in predicting global and local problems), (b) which human behaviors or cultural practices would contribute to solve these problems (behavioral science may test which practices are effective to achieve the proposed objectives), and (c) what techniques promote development of these behaviors and practices.

\section{Concluding Remarks}

Skinner pioneered a science of human behavior and a technology of behavior that, in his opinion, should contribute to a better life and a better world, through modification of behavior and promotion of social changes. Skinner was, at least since Walden Two, already concerned about the future of humanity and how a technology of behavior would be used to improve it. Given the current challenges that threaten the survival of cultures and of our own species, we may consider that Skinner's ideas anticipated the challenges to the survival of humanity posed by immediate and remote consequences of behavioral practices. According to Skinner and behavior analysts in general, behavior is lawful and science can discover its controlling variables. The 
advancement of a science of behavior, therefore, gives rise to a technology, which can contribute to change cultural practices in order to guarantee the survival of the culture and the species. ${ }^{15}$

Skinner (1953/1965) claimed that science can accelerate the practice of changing practices. He asserted that science can make remote consequences of behavior effective. He, as well as many behavior analysts, stressed the urgent need that science and technology speed up the design of practices with positive survival value.

Skinner's proposals give rise to ethical questions. Technological choices require ethical discussion, or, at least, inspire ethical questions. Skinner's Radical Behaviorism argues that the science of behavior is also a science of values, whose basic assumption is to deny ontological distinction between facts and values.

In spite of the moral relativism of Skinner's metaethics, behavioral technology must have values to govern its use. The main value prescribed by Skinner is the good of the culture, that should be in balance with the welfare of individuals in a well-designed culture. As Richelle (1993/2003) points out, "Individual happiness converges here with the future of the species: education, as concerned with the future of society, should aim at preserving diversity, which is recognized as an essential factor in survival, in a Darwinian sense" (p. 175).

The progress of behavioral science and behavioral technology, particularly educational technology, has been remarkable. Even a cognitive psychologist like Roediger (2000) admitted that, to solve behavioral problems, one needs to resort to behavioral technology. A powerful educational technology is evolving, particularly to address the education and treatment of children with developmental disabilities. It is doubtful, however, that behavioral technology has developed sufficiently enough to support the design of a whole society, as advocated by Skinner, especially in his early works. Technology of teaching, in particular, has been very effective to teach existing knowledge. Theoretically, a technology of teaching could be applied to educate students to solve problems, to be creative, to have self-control and self-regulation, and to think independently. Steps in this direction have undoubtedly been taken. Whole schools have been designed based on behavioral technology, with promising results. Implementing behavioral technology in individual schools is not the same as designing the education of a whole culture, and it is not clear if and how this would be feasible. Despite Skinner's arguments, applying a behavioral technology to a whole society would still raise the questions of who would set the goals, who would make decisions, and how. A technology of teaching may be employed to make individuals free and it also could be employed to exploit them for the benefit of those in charge of controlling agencies. Thus, technology is not devoid of values. One can even question whether scientific knowledge itself can be ethically neutral, since the scientist is the product of a culture that established certain things as good and others as bad.

\section{References}

Castro, M. S. L. B. (2013). O naturalismo ético no behaviorismo radical de B. F. Skinner. (Tese de doutorado). Universidade Federal de São Carlos, São Carlos, Brasil.

Chiesa, M. (2003). Sobre la meta-ética, la ética normativa y el conductismo. Revista Latinoamericana de Psicologia, 35 (3), 289-297.

\footnotetext{
${ }^{15}$ As pointed out by Castro (2013), Skinner seems at times to use interchangeably survival of the culture (presumably the Western culture to which he belonged) and survival of humanity, but in his later works he seemed more concerned with survival of humanity. Of course, no culture would survive if humanity were to perish.
} 


\section{MELO, CASTRO, \& DE ROSE}

Diamond, J. (2005). Collapse. How societies choose to fail or succeed. New York, NY: Penguin.

Dewey, J. (1929). Experience and nature. La Salle, IL: Open Court.

Dittrich, A., \& Abib., J. A. D. (2004). O sistema ético skinneriano e consequiências para a prática dos analistas do comportamento. Psicologia: Reflexão e Crítica, 17(3), 427-433. doi: 10.1590/S0102-79722004000300014

Glenn, S. S. (1986). Metacontingencies in Walden Two. Behavior Analysis and Social Action, 5, 2-8.

Glenn, S. S. (1991). Contingencies and metacontingencies: Relations among behavioral, cultural, and biological evolution. In P.A. Lamal (Ed.), Behavioral analysis of societies and cultural practices (pp. 39-73). New York, NY: Hemisphere Publishing Corporation.

Glenn, S. S., \& Malott, M. (2004). Complexity and selection: Implications for organizational change. Behavior and Social Issues, 13, 89-106. doi:10.5210/bsi.v13i2.378

Harris, M. (1974). Cows, pigs, wars, and witches: The riddles of culture. New York, NY: Vintage Books.

Lehman, P. K., \& Geller, E. S. (2004). Behavior analysis and environmental protection: accomplishments and potential for more. Behavior and Social Issues, 13, 13-32. doi: 10.5210/bsi.v13i1.33

Leigland, S. (2005). Variables of which values are a function. The Behavior Analyst, 28, 133-142.

Malott, M. E., \& Glenn, S.S. (2006). Targets of intervention in cultural and behavioral change. Behavior and Social Issues, 15, 31-56. doi:10.5210/bsi.v15i1.344

Mattaini, M. A. (2006). Will cultural analysis become a science? Behavior and Social Issues, 15, 68-80. doi:10.5210/bsi.v15i1.380

Melo, C. M. (2008). A concepção de homem no behaviorismo radical e suas implicações para a tecnologia do comportamento. (Tese de doutorado). Universidade Federal de São Carlos, São Carlos, Brasil.

Melo, C. M., \& De Rose, J. C. C. (2012). O conceito de sobrevivência das culturas em B. F. Skinner: Um diálogo com o Materialismo Cultural de Marvin Harris. Psicologia Teoria e Pesquisa, 28(1), 119-128. doi:10.1590/S0102-37722012000100015

Murphy, J. P (1990). Pragmatism: From Peirce to Davidson. Boulder, CO: Westview.

Plumb, J. C., Stewart, I., Dahl, J., \& Lundgren, T. (2009). Search of meaning: Values in modern clinical behavior analysis. The Behavior Analyst, 32(1), 85-103.

Proudfoot, M., \& Lacey, A. R. (2010). The Routledge dictionary of philosophy (4 ${ }^{\text {th }}$ ed.). Milton Park, Abingdon: Routledge.

Richelle, M. N. (2003). B. F. Skinner: A Reappraisal. New York, NY: Psychology Press. (Original work published 1993).

Roediger, H. L. (2004). What happened to behaviorism. American Psychological Society (APS) Observer, 17(3).

Rorty, R. (1979). Philosophy and the mirror of nature. Princeton, NJ: Princeton University Press.

Ruiz, M., \& Roche, B. (2007). Values and the scientific culture of behavior analysis. The Behavior Analyst, 30(1), $1-16$.

Skinner, B. F. (1965). Science and human behavior. New York, NY: Free Press. (Original work published 1953).

Skinner, B. F. (1968). The technology of teaching. New York, NY: Appleton-Century-Crofts.

Skinner, B. F. (1969a). The phylogeny and ontogeny of behavior. In B. F. Skinner, Contingencies of reinforcement: A theoretical analysis (pp. 172-217). New York, NY: Appleton-Century-Crofts. (Original work published 1966).

Skinner, B. F. (1969b). Utopia as an experimental culture. In B. F. Skinner, Contingencies of reinforcement: A theoretical analysis (pp. 29-49). New York, NY: Appleton-Century-Crofts.

Skinner, B. F. (1976). About behaviorism. New York, NY: Vintage Books. (Original work published 1974).

Skinner, B. F. (1978). The shaping of phylogenic behavior. In B. F. Skinner, Reflections on behaviorism and society (pp. 163-170). Englewood Cliffs, NJ: Prentice-Hall. (Original work published 1975).

Skinner, B. F. (1981). Selection by consequences. Science, 213, 501-504. doi:10.1126/science.7244649

Skinner, B. F. (1984). The shaping of a behaviorist. New York, NY: University Press. (Original work published 1979).

Skinner, B. F. (1987). Why we are not acting to save the world. In B. F. Skinner, Upon further reflection (pp. 0114). Englewood Cliffs, NJ: Prentice-Hall.

Skinner, B. F. (1990). Can psychology be a science of mind? American Psychologist, 45, 1206-1210. doi:10.1037/0003-066X.45.11.1206

Skinner, B. F. (2002). Beyond freedom and dignity. Indianapolis, IN: Hackett Publishing Company (Original work published 1971).

Skinner, B. F. (2003). The technology of teaching. Cambridge, MA: B. F. Skinner Foundation. (Original work published 1968). 


\section{CULTURE, ETHICS, AND TECHNOLOGY IN B. F. SKINNER}

Skinner, B. F. (2005). Walden Two. Indianapolis, IN: Hackett Publishing Company (Original work published 1948).

Tourinho, E. Z., \& Vichi, C. (2012). Behavioral analytic research of cultural selection and the complexity of cultural phenomena. Revista Latinoamericana de Psicologia, 44(1), 169-179.

Vichi, C., Andery, M. A. P., \& Glenn S. S. (2009). A metacontingency experiment: The effects of contingent consequences on patterns of interlocking contingencies of reinforcement. Behavior and Social Issues, 18, 4157. doi:10.5210/bsi.v18i1.2292

Watts, M. W. (1975). B. F. Skinner and technological control of social behavior. The American Political Science Review, 69, 214-227. 